\title{
Focus on collagen: in vitro systems to study fibrogenesis and antifibrosis - state of the art Clarice ZC Chen ${ }^{1,2}$ and Michael Raghunath*1,3
}

\author{
Address: ${ }^{1}$ Division of Bioengineering, Faculty of Engineering, National University of Singapore, DSO Building (Kent Ridge), Medical Drive, \\ Singapore, ${ }^{2}$ UUS Graduate School for Integrative Sciences and Engineering, National University of Singapore, Singapore and ${ }^{3}$ Department of \\ Biochemistry, Yong Loo Lin School of Medicine, National University of Singapore, Singapore \\ Email: Clarice ZC Chen - clarice@nus.edu.sg; Michael Raghunath* - bierm@nus.edu.sg \\ * Corresponding author
}

Published: 15 December 2009

Fibrogenesis \& Tissue Repair 2009, 2:7 doi:10.1186/1755-1536-2-7

This article is available from: http://www.fibrogenesis.com/content/2/l/7

(C) 2009 Chen and Raghunath; licensee BioMed Central Ltd.

This is an Open Access article distributed under the terms of the Creative Commons Attribution License (http://creativecommons.org/licenses/by/2.0), which permits unrestricted use, distribution, and reproduction in any medium, provided the original work is properly cited.
Received: 19 October 2009

Accepted: 15 December 2009

\begin{abstract}
Fibrosis represents a major global disease burden, yet a potent antifibrotic compound is still not in sight. Part of the explanation for this situation is the difficulties that both academic laboratories and research and development departments in the pharmaceutical industry have been facing in reenacting the fibrotic process in vitro for screening procedures prior to animal testing. Effective in vitro characterization of antifibrotic compounds has been hampered by cell culture settings that are lacking crucial cofactors or are not holistic representations of the biosynthetic and depositional pathway leading to the formation of an insoluble pericellular collagen matrix. In order to appreciate the task which in vitro screening of antifibrotics is up against, we will first review the fibrotic process by categorizing it into events that are upstream of collagen biosynthesis and the actual biosynthetic and depositional cascade of collagen I. We point out oversights such as the omission of vitamin C, a vital cofactor for the production of stable procollagen molecules, as well as the little known in vitro tardy procollagen processing by collagen C-proteinase/BMP-I, another reason for minimal collagen deposition in cell culture. We review current methods of cell culture and collagen quantitation vis-à-vis the high content options and requirements for normalization against cell number for meaningful data retrieval. Only when collagen has formed a fibrillar matrix that becomes cross-linked, invested with ligands, and can be remodelled and resorbed, the complete picture of fibrogenesis can be reflected in vitro. We show here how this can be achieved. A well thought-out in vitro fibrogenesis system represents the missing link between brute force chemical library screens and rational animal experimentation, thus providing both cost-effectiveness and streamlined procedures towards the development of better antifibrotic drugs.
\end{abstract}

Fibrosis - ubiquitous problem and global burden Repair of damaged tissues is an essential biological process which allows directed replacement of dead or damaged cells with connective tissue after injury. The repaired area is addressed as a scar. Hence, scarring represents a survival mechanism that is conserved throughout evolution and appears to be most pronounced in humans. If this wound healing process goes awry, fibrosis results, often causing an excessively large scar or the scarry transformation of organ parts or whole organs. Besides local scarring at sites of acute trauma, a variety of other causes, such as chronic infections, chronic exposure to alcohol and other toxins, autoimmune and allergic reactions, radio- and chemotherapy, can all lead to fibrosis. This 
pathological process, therefore, can occur in almost any organ or tissue of the body and, typically, results from situations persisting for several weeks or months in which inflammation, tissue destruction and repair occur simultaneously. In this setting, fibrosis most frequently affects the lungs, liver, skin and kidneys. There are approximately 5 million cases of idiopathic lung fibrosis globally [1], not counting rare disorders like cystic fibrosis or very common ones such as asthma. Chronic hepatitis virus $\mathrm{B}$ and $\mathrm{C}$ are a major cause of liver fibrosis/cirrhosis which currently ranks 18th of the global disease burden [2]. Scar formation after myocardial infarction can on one hand prevent the injured myocardium from dilatation and rupture but, on the other hand, it can impair cardiac function through increasing ventricular wall stiffness [3]. Atherosclerotic lesions contain fibrotic tissue which can occupy up $87 \%$ of total plaque area [4].

Peri-implantational fibrosis represents a current clinical roadblock in regenerative medicine, which is gaining attention in the tissue engineering field. Every implant is surrounded by a fibrotic tissue reaction that depends on the material, its surface and its degradation profile [5-7]. This is a consequence of chronic local inflammation and a reflection of the host's tissue attempt to destroy the implant or to cope with it. If destruction is not an option, the implants get wrapped in a fibrous shroud with sparse or no vascularization, so that it becomes effectively isolated from the surrounding tissue. This is seen in artificial ligaments $[8,9]$, implanted biosensors [10,11], joint implants [12,13], breast implants [14,15], encapsulated tissues/cells [16,17], drug delivery systems [18] and eye implants $[19,20]$, and regularly impairs the proper function of the implant. This has prompted the field to alter surface structures and coatings to contain this problem [5,21-27]. A potential strategy could be to develop biomaterials that will deliver an antifibrotic substance locally $[15,28,29]$.

It becomes clear that the development of effective antifibrotics is an important unmet clinical need and with it remains the necessity for rapid in vitro screening tools to characterize lead antifibrotic compounds before they are tested in animal models. This review will focus on the current state of the art to emulate a fibrotic process in vitro, the associated challenges and pitfalls and suggestions on how to address them.

Fibrogenesis in vivo - complexity and key players In order to appreciate the task which in vitro screening of antifibrotics is up against, we shall dissect the fibrotic process into two categories: first, events that are upstream of collagen biosynthesis; and, secondly, the biosynthetic and depositional cascade of collagen I.

\section{Upstream events of fibrosis - cellular players in vivo}

Trauma disrupts the anatomical cohesion of tissue structures, most evident by bleeding which indicates breakage of blood vessels and disruption of their endothelial lining. This immediately induces a haemostatic response encompassing platelet aggregation, blood clot formation and accumulation of provisional ECM [30]. Damaged epithelia secrete cytokines, growth factors and chemoattractants for mononuclear cells to phagocytose cellular debris at the site of injury and for fibroblasts to deposit collagen and remodel it. Thus, a scar is formed that eventually matures. The origin of these fibroblasts is currently a matter of debate. They are either differentiating homing mesenchymal stem cells [31], fibrocytes from the blood circulation [32] or are derived from epithelia via epithelial-mesenchymal transition (EMT) [33]. The fibroblasts involved in scarring have a myofibroblast phenotype characterised by $\alpha$-smooth muscle actin ( $\alpha$-SMA) expression, increased secretion of collagen type I and III, and contractility [30]. These cells are believed to be responsible for the majority of collagen production in most organs.

\section{'Soluble' factors mediating fibrosis}

The cellular effectors of fibrosis are activated and phenotypically modulated by humoral players, namely chemokines, growth factors and cytokines. Most notorious is transforming growth factor $\beta 1$ (TGF- $\beta 1$ ) which supports wound healing and repair. Under pathological conditions, TGF- $\beta 1$ coordinates a cross-talk between parenchymal inflammatory and collagen-expressing cells, and plays a key role in fibrosis progression. TGF- $\beta 1$ is often referred to as a 'soluble' factor. We use quotation marks here because TGF- $\beta 1$ is stored in its latent form bound to TGF- $\beta 1$ binding proteins in the matrix [34], and can in its active form be scavenged and possibly neutralized by decorin-mediated binding into the ECM [35,36] (for review see [37]).

Along with factors such as the epithelial growth factor, basic fibroblast growth factor and interleukin-1, TGF- $\beta 1$ appears to play a key role in EMT [32]. The connective tissue growth factor [38] and platelet-derived growth factor [39] have also been reported to be involved in fibrosis (for a more in-depth review on cytokines and molecular mechanisms involved in fibrogenesis, refer to [40]). Inflammation typically precedes fibrosis, although it has been demonstrated that fibrosis is not always driven by inflammation. This suggests that the mechanisms that regulate fibrogenesis are, to a certain extent, distinct from those regulating inflammation [41]. This may explain the lack of efficacy of anti-inflammatory compounds in the treatment of fibrotic disease [42]. Antifibrotic strategies at the upstream level aim to interfere with fibrotic growth factors and make use of interfering antibodies [43-46], small 
molecules [39,47], proteins [48,49], antisense technology $[50,51]$ or the use of human recombinant TGF- $\beta 3$. TGF- $\beta 3$ is an alleged TGF- $\beta 1$ antagonist that has shown some promise in phase III clinical trials in a prophylactic setting of small skin wounds [52].

\section{Understanding the last mile of the fibrotic pathway}

Irrespective of upstream events that trigger and entertain fibrosis, the final product of cellular activity is the massive deposition of collagen which results in scar formation, organ or peri-implantational fibrosis. Therefore, we would like to turn now to the obvious target in fibrosis, namely the biosynthetic pathway of collagen itself.

The overall amount of collagen deposited by fibroblasts is a regulated balance between collagen synthesis and collagen catabolism, which is a carefully controlled process. During a pathological maturation and remodelling phase, collagen synthesized by fibroblasts exceeds the rate at which it is degraded such that the net amount of collagen continues to increase. There are several key points along the collagen biosynthesis pathway that can be targeted to effect a net reduction of collagen secretion and/or deposition (Figure 1). Transcription interference can be affected using histone deacetylase inhibitors $[53,54]$ or substances like halofuginone $[55,56]$. At the post-transcriptional level, siRNA targeting growth factors and key players have been investigated $[50,51,57]$ and, recently, we and others have suggested the use of microRNAs [58,59]. Interfering with post-translational modifications by inhibiting prolyl-4 hydroxylase renders collagen triple helices less thermostable and prevents their secretion [59,60], downregulation of collagen chaperone hsp47 does likewise $[61,62]$. At the extracellular level, inhibition of procollagen C-proteinase/BMP1 prevents the removal of the C-terminal propeptide from the procollagen I molecule and, thus, the supramolecular assembly of collagen into fibrils $[47,59]$. Inhibition of lysyl oxidase mediation of intermolecular cross-links between collagen triple helices can reduce collagen content of the ECM, presumably by rendering collagen aggregates more susceptible to proteolytic remodelling [63]. Similarly, the administration of hepatocyte growth factor [64] and matrix metalloproteinase 1 (MMP1) $[48,49]$ increases collagen turnover in the ECM. It becomes clear that a meaningful in vitro system for the testing and characterization of antifibrotics should be able to emulate the above described complete collagen matrix formation cascade, encompassing its biosynthesis and all post-translational (intra- and extra-cellular) modifications that give rise to a stable supramolecular assembly, and also ideally allow the study of remodelling/fibrolysis. For the sake of convenience and efficiency for screening purposes, quantitation of collagen and other proteins of interest should preferentially be in and from one well.

\section{Fibrogenesis in vitro - constraints and options}

The task of emulating collagen matrix formation in vitro has been surprisingly difficult, partly due to the omission of important cofactors and partially because of intrinsic properties of contemporary cell culture conditions that still are largely unknown. We will discuss these problems and their solutions.

\section{Biosynthetic issues - getting collagen made and deposited in vitro}

(1) The first challenge for in vitro fibrogenesis is the sufficient production of collagen and its subsequent incorporation into a pericellular matrix. The omission of ascorbic acid in cell culture $[38,65,66]$ results in minimal production and deposition of collagen on the cell layer. Ascorbate is a crucial cosubstrate of the enzymes responsible for the post-translational hydroxylation of prolyl and lysyl residues necessary for rendering the collagen triple helix thermostable, as well as for the extracellular cross-linking of collagen fibers, respectively $[67,68]$. In other words, scurvy can exist in cell culture. However, like its counterpart in vivo, it can be easily treated in vitro by the administration of ascorbate. On the other hand, L-ascorbic acid has a short half-life in culture and completely oxidizes after 3 days, so use of the stable form of ascorbate, such as a magnesium salt of L-ascorbic acid 2-phosphate hexahydrate, is highly recommended [67].

About 23\% of the collagen molecule is composed of proline and hydroxyproline. As a non-essential amino acid, proline is synthesized from arginine/ornithine via the urea cycle and glutamate (directly or indirectly from glutamine via glutaminase) through the citric acid cycle. Clinical observations in burn patients suggest a drain of arginine, ornithine and glutamate [69], while wound fluid proline levels are at least $50 \%$ higher than plasma levels, suggesting active import of proline into the wound [70]. Providing additional proline or glutamine in the diet to enhance collagen biosynthesis, however, does not result in increased collagen accumulation. In contrast, arginine, and ornithine supplementation are most effective in increasing collagen deposition [71]. As cell culture media contains L-arginine and are usually supplemented with L-glutamine, direct proline supplementation of cell cultures in static and bioreactor conditions is not necessary for increasing collagens synthesis, as also shown recently [72]. However, systematic studies of proline-precursor supplementation in vitro under conditions of increased synthesis and deposition have yet to be conducted.

(2) Even under ascorbate supplementation, fibroblasts deposit only minimal amounts of secreted collagen I into their matrices. The reason for this lies in the tardy procollagen C-proteinase/BMP1 activity under current aqueous 


\section{Intracellular}
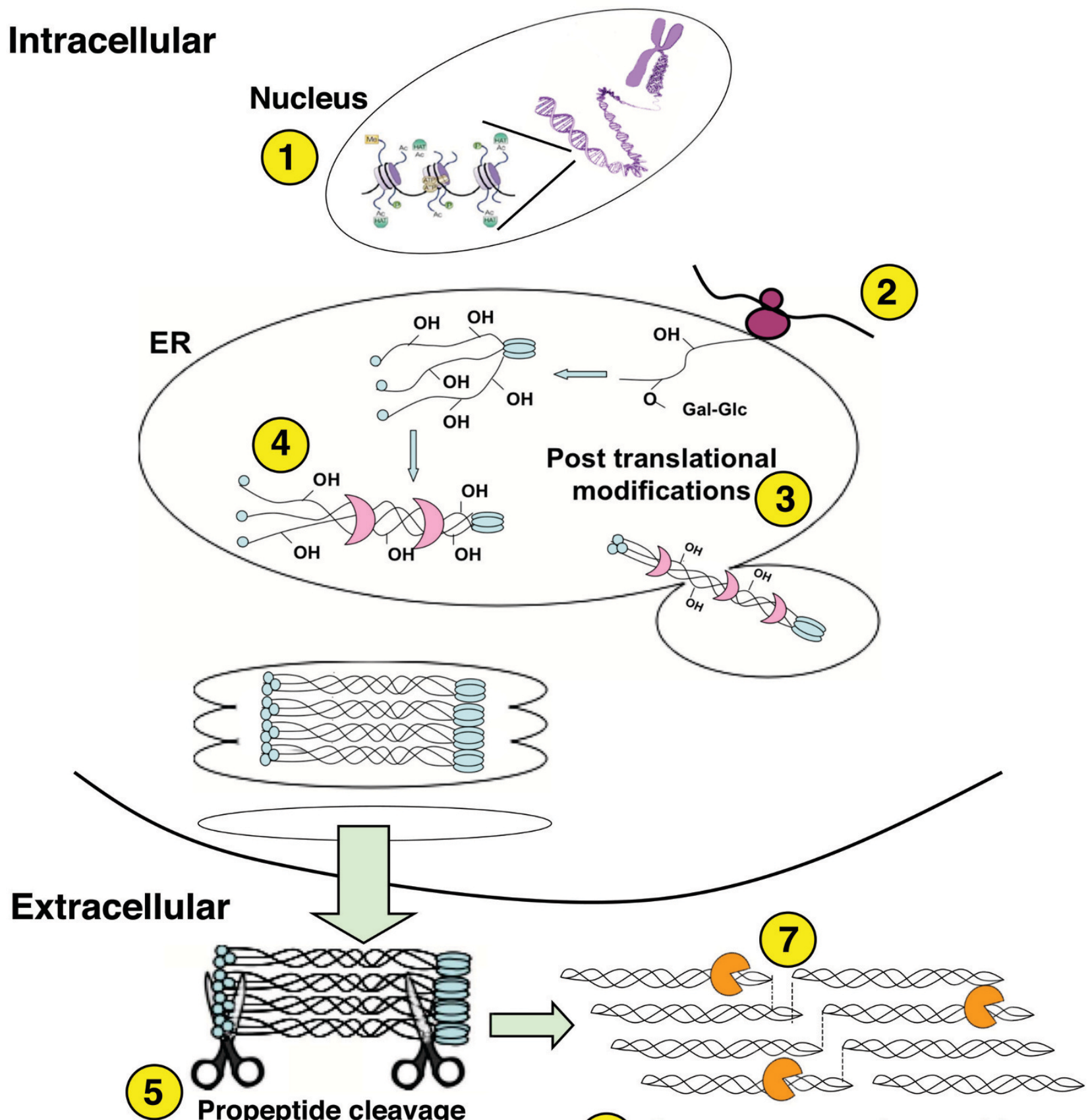

(6) Quarter staggered assembly
and cross-linking of fibrils

\section{Figure I}

Potential points of interference along the collagen biosynthesis pathway. (I) Epigenetic level: HDAC inhibitors. (2) Post-transcriptional level: mRNA translation is reduced by miRNAs/siRNAs. (3) Post-translational level: prolyl-4-hydroxylase inhibitors reduce the stability of the procollagen triple helix. (4) Reduction/inhibition of the collagen chaperone hsp47 (pink crescent symbol) also reduces stability of the procollagen triple helices, resulting in intracellular retention and degradation. (5) Post-secretional level: Inhibition of procollagen proteinases (scissors symbol) prevents deposition of insoluble collagen molecules on the cell layer. (6) Collagen crosslinking: Inhibition of lysyl oxidase (LOX) hypothetically renders the collagen more susceptible to degradation. 7) An increase of MMPI (orange Pacman symbol) results in faster collagen degradation and turnover. 
culture conditions. This results in an accumulation of unprocessed procollagen in the cell culture medium [73] where it does not belong and is discarded with every medium change. Analytical methods have, therefore, mostly focused on the convenient measurement of procollagen secreted into culture medium. This may be sufficient to assess compounds that primarily influence biosynthesis and/or secretion, but it would not allow assessment of any later step in collagen matrix formation.

To improve collagen deposition in cell culture, a fibroplasia model was developed using hyperconfluent human dermal fibroblasts exposed to TGF- $\beta 1$ for up to 1 month to allow the formation of a fibroplastic tissue [63]. In an abbreviated form ( 8 days TGF- $\beta 1$ treatment) this model is in use at Pfizer Global R\&D (Sandwich, Kent). This model moves closer to emulating the entire collagen biosynthesis pathway as it allows the assessment of procollagen C-proteinase inhibitors, which are predicted to interfere with collagen deposition [47]. Destructive analysis of deposited collagen by high-performance liquid chromatography of 4-hydroxyproline is performed on the insoluble culture fraction. Our laboratory has systematically developed technology to accelerate collagen deposition in vitro by introducing macromolecules into the culture medium. We have developed two deposition technologies that differ in terms of speed and morphology of the deposited collagen. The first approach employs charged macromolecules such as dextran sulphate $500 \mathrm{kDa}(\mathrm{DxS})$ and polysodium-4-styrene sulfonate [61]. DxS leads to a granular deposition of collagen within 48-72 h, exceeding that of non-crowded cultures by 20- to 30 -fold within the same time frame. The second approach using neutral macromolecules in a Ficoll cocktail (Fc) [59] increases collagen deposition 10-fold in 6 days and in a reticular deposition pattern (Figure 2B). Both approaches are based on the creation of the excluded volume effect as explained elsewhere $[61,73,74]$. Briefly macromolecules drive reaction partners into closer collaboration resulting in improved protein folding and protein-protein interactions. In the case of fibrogenic cell culture, the conversion of procollagen to collagen is sped up as well as the supramolecular assembly of collagen triple helices to form fibres.

\section{Quantitative issues - measuring collagen and normalizing the data}

(3) Determination of the amount of collagen produced in vitro is the next challenge, and this can be done in a variety of ways ranging from simple colorimetric assays to elaborate chromatographic procedures using radioactive and non-radioactive material. What most of these procedures have in common is the need to destroy the cell layer to obtain solubilized collagen from the pericellular matrix. The oldest established colorimetric method employs chloramine-T method to measure hydroxyproline [75]. The destructive pre-solubilization requirement of collagen for this assay, lack of specificity in discriminating between collagen types, as well as a lack of internal normalization within samples, are disadvantages in a screening setting. The Sirius dye has been used since 1964 to identify collagen in histology specimens [76,77]. It is based on the selective binding of Sirius Red F3BA to collagen. Subsequent elution with sodium hydroxide-methanol and read-out at $540 \mathrm{~nm}$ can be done in cuvettes, in microtiterplates with collagen extract adsorbed to the plastic and using microplate readers $[66,78,79]$. Biocolor Ltd (County Antrim, Northern Ireland, UK) made the Sircol ${ }^{\mathrm{TM}}$ Collagen Assay commercially available in 2007. Precipitation of soluble collagen with the Sirius Red dye is required prior to release of the dye with an alkali. In our hands, this assay grossly overestimates collagen and procollagen secreted into cell culture medium due to interference of non-collagenous serum proteins, so we would recommend prepurification (peptic digest and ultrafiltration) to improve both sensitivity and specificity (Ricky R Lareu, Dimitrios Zeugolis and Michael Raghunath, unpublished experiments). An interesting solution appears to be the adsorption of this dye onto collagen deposited on the cell layer in culture [80]. This was recently suggested in a modified version for the testing of antifibrotic agents [66], although this screening system did not use or recommend the addition of ascorbic acid [66]. Various enzyme-linked immunoassays can be used to quantify specific collagen types such as coating collagen extracts onto multiwell plates followed by detection using antibodies, sandwich assays and competitive enzyme immunoassays. These assays are very suitable for assessing soluble collagen from culture media but would require extraction and dialysis procedures to release insoluble collagen from pericellular matrices. In this case, normalization for differences between protein amounts or cell numbers in samples is not possible. The determination of the hydroxyproline/ proline ratio via HPLC is based on total hydrolysis of protein samples, separation of hydroxyproline from proline and back calculating the possible collagen content of the sample [81]. While this method allows for the analysis of any given biological material in experienced laboratories, it is not amenable to a screening setting and would not allow for normalisation or discrimination between different collagen types, the same holds true for metabolically labelled cell cultures with the attending issues of isotope handling [82]. Similar issues arise with gas chromatography/mass spectrometry requiring derivatization using trifluoroacetylation and methanol esterification of 4hydroxyproline in collagen. Incorporation of the stable isotope of oxygen, ${ }^{18} \mathrm{O}_{2}$, into collagen is also possible with this method and enables the examination of collagen synthesis in vitro [83]. Polyacrylamide gel electrophoresis can be very collagen specific using metabolic labelling of cell cultures with radiolabelled amino acids glycine and pro- 
A

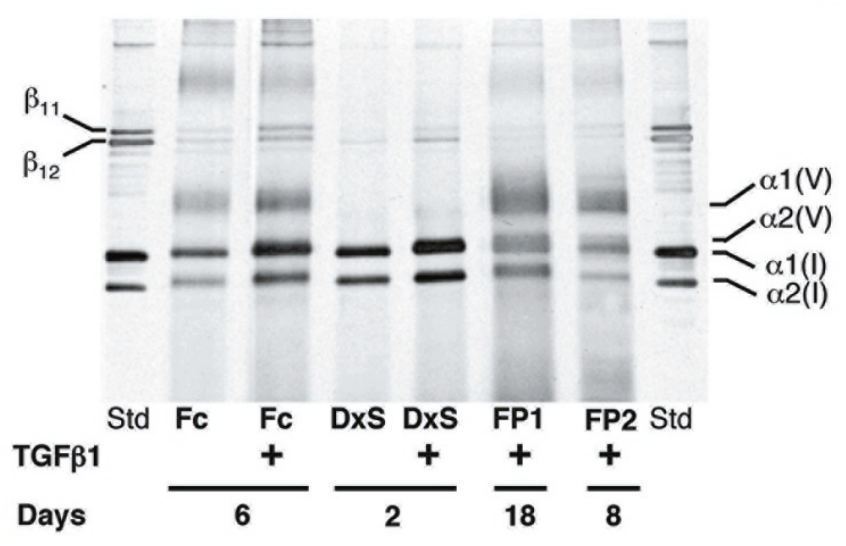

B

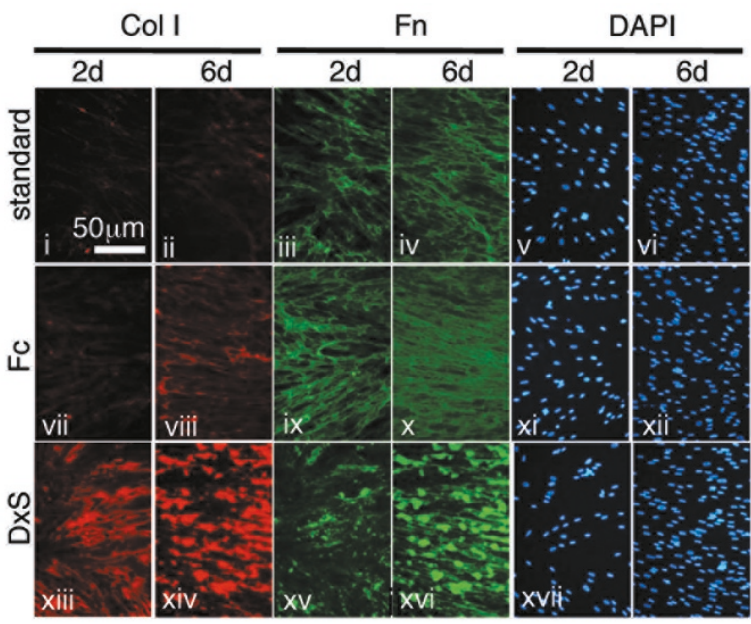

D

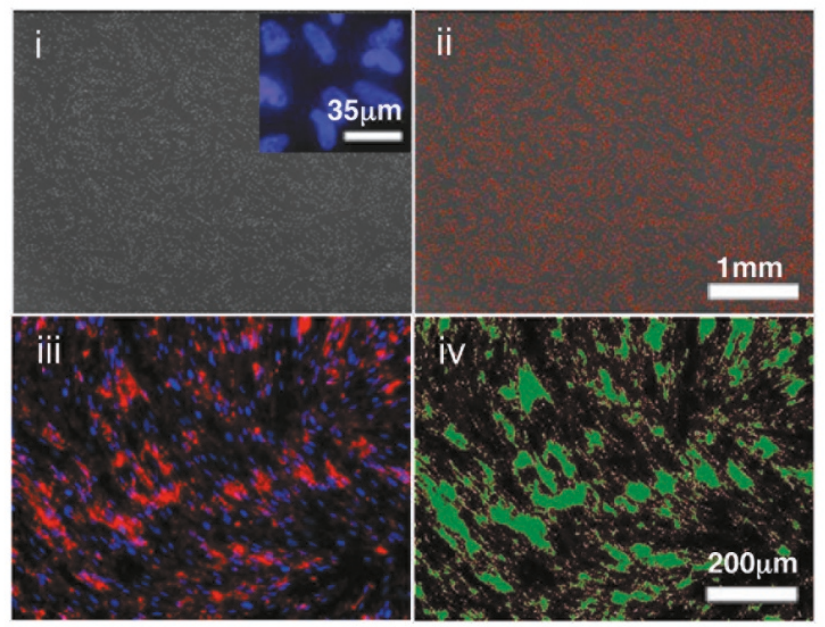

Figure 2

The Scar-in-the-Jar system combines enhanced collagen deposition with optical analysis for in situ quantitation. (A) Cell layers were pepsin digested, resolved by sodium dodecyl sulphate - polyacrylamide and silver stained. In comparison with fibroplasia models (FPI: Ref [6I], FP2: Ref [45]), macromolecular crowding increased matrix formation including stronger lysyl oxidase-mediated cross-linking in both deposition modes (rapid: dextran sulphate [DxS]; accelerated: Ficoll cocktail [Fc]), within a shorter time frame. Note: the presence of collagen $\mathrm{V}$ in FP and the accelerated deposition mode and its absence in the rapid deposition mode. Collagen $V$ is usually absent from fibrotic tissue; hence, the extracellular matrix obtained in the rapid deposition mode will probably be more similar to a fibrotic matrix. (B) Cell layers were immunostained for collagen I and fibronectin. Cell nuclei were stained with 4', 6-diamidino-2-phenylindoldilactate (DAPI). The rapid deposition mode (negatively charged, DxS) produces granular collagen I and fibronectin within 2 days, and the accelerated mode (neutral, Fc) produces collagen I with a reticular deposition pattern within 6 days. Therefore, the amount, velocity and morphology of deposited collagen can be manipulated depending on the macromolecules used. (C) Optical analysis of deposited collagen I using a 2× objective, eliminated corner auto-fluorescence in the four corner fields with triangular masks to conceal these regions during quantitation. (D) Cytometry and quantitation of the area of deposited collagen I in a 24-well multiplate format enabled identification of antifibrotic substances that perturb the collagen biosynthesis pathway resulting in a net reduction of deposited collagen I. (i) DAPI-stained nuclei at 20x total magnification in monochrome pseudocolour, 600× magnification (inset). (ii) Red scored nuclei by Count Nuclei module for cytometry. (iii) Immunostained deposited collagen I. (iv) Regions with fluorescent pixel intensity above a selected value based on controls are demarcated by the software in green for quantitation of deposited collagen I area at I00x magnification. This figure is reproduced with permission (Ref [59]). 
line [84] and subsequent detection of radioactive bands using fluorography [85]. Metabolic labelling can be replaced with safer and very sensitive silver staining or immunoblotting [61]. The latter has the advantage of differentiating between various collagen types and comparison with an internal standard like actin as a cell mass equivalent for normalization. Collagen antibodies tend to recognize protein conformation in addition to sequence specificity, which can pose a problem for the detection of denatured collagen $\alpha$-chains in sodium dodecyl sulphatepolyacrylamide gel electrophoresis (SDS-PAGE), hence native PAGE might be an alternative option [86]. All gel electrophoresis-based approaches are excellent qualitative and quantitative back-up techniques. However, their laboriousness would exclude them as screening tools.

(4) Normalization of data to account for cell number variations is another important consideration. Most of the methods discussed above lack the option of normalization and the use of parallel cultures subjected to the separate measurement of total protein or DNA content. In any case, cell density influences the amount of collagen deposited: in fact, subconfluent cultures produce the most collagen [87]. Depending on the substance screened, inhibition or stimulation of proliferation, or cytotoxicity may occur. As this certainly will impact on the collagen amount secreted/deposited, well-to-well variances not withstanding, the acquired data must account for these changes in cell number/density. Data normalization methods involve the destruction of cell layers to quantify housekeeping proteins by Western blot or DNA $[81,83]$. This not only increases sample-processing steps, but also cumulates error.

\section{Qualitative issues - looking beyond collagen I}

(5) Fibrosis is not only characterized by an excess buildup of collagen I but, depending on the tissue context, other proteins might be of interest. Also, the transition of fibrogenic cells from a quiescent fibroblast stage to a fibrotic myofibroblast phenotype should be considered. Markers such as $\alpha$-SMA or fibroblast activation protein- $\alpha$ [88] are up-regulated in stimulated fibroblasts and a survey of the production and deposition of non-collagenous extracellular matrix (ECM) proteins as an internal control for the action of antifibrotic agents would be desirable. As well as capturing the actual number of cells in a given well, options for a high content read-out covering as many of the above markers as possible in addition to collagen I would constitute an ideal antifibrotic screening system.

\section{A current solution: the Scar-in-a-Jar}

The Scar-in-a-Jar has been developed in our laboratory in order to address the problems of in vitro fibrogenesis discussed above. This system: (1) solves the problem of tardy collagen deposition; (2) quantitatively measures relative changes in collagen I deposition via immunofluorescence and in situ optical analysis; (3) allows for high content screening within a single well including $\alpha$-SMA and another ECM protein of choice; and (4) while implementing normalization for cell number by counting nuclei via 4',6-diamidino-2-phenylindoldilactate (DAPI) staining [59]. As discussed above, the addition of charged and neutral macromolecules into culture medium dramatically enhances the deposition of collagen into the pericellular matrix [61] (Figure 2B), within a shorter time, to a greater extent and degree of cross-linking than possible in both fibroplasia models by Clark et al. (1997) [63] and Fish et al. (2007) [47] (Figure 2A). In both cases, enhanced collagen deposition reduces culture time to $48 \mathrm{~h}(\mathrm{DxS})$ and 6 days $(\mathrm{Fc})$, prior to optical quantitation. TGF- $\beta 1$ addition is optional. For optical analysis, samples in a 24-well format are immunostained for collagen I and fibronectin, and cell nuclei are stained with DAPI. Automated image acquisition using a $2 \times$ objective is performed and the area of collagen I and fibronectin per cell is ascertained using the Metamorph ${ }^{\circledast}$ Imaging System software (Figure 2C-D).

The Scar-in-a-Jar enables the analysis of proteins-of-interest and cell enumeration all within a single-well, thus minimizing processing steps, material loss and sample variation. Cell enumeration can give an indication of potential anti-proliferative effects of a compound and allows for correction of protein production to account for the variance in cell numbers due to that compound. We also demonstrated its capability to discern the reduction of deposited collagen by known and novel inhibitors targeting various points of the collagen biosynthesis pathway from the epigenetic to the extracellular level, including two C-proteinase inhibitors, FSY002, originally developed in a German pharmaceutical company [89] and PCP56 from Pfizer (NY, USA) [47]. PCP56 demonstrated efficacy in agreement with an earlier report on the abridged fibroplasia model [47] but FSY002 did not work in our system. FSYO02 has an interesting history. This phosphinate inhibitor did inhibit purified C-proteinase in the test tube and an $\mathrm{IC}_{50}$ value could be obtained [89]. However, tests in conventional monolayer fibroblast culture proved inconclusive and we have to conclude in hindsight that this was due to tardy C-proteinase activity. Running this substance in our system with fully active Cproteinase activity revealed its ineffectiveness. At this point in time, optical analysis is unable to discern a reduction in collagen cross-links if there is no net collagen reduction on the cell layer [59]. Hence, the testing of lysyl oxidase inhibitors will be better analysed by the biochemical analysis method employing pepsin digestion of cell layers followed by SDS-PAGE and silver staining to visualize collagen cross-links (Figure 2A) [85]. 
The combination of short culture time, rapid collagen biosynthesis, complete deposition, together with optical analysis that circumvents the need for protein extraction, makes the Scar-in-a-Jar a convenient assay that remains in a single well from start to finish.

\section{Future developments}

Besides the current use of fibroblasts, this system has the flexibility and potential to screen the effect of potential antifibrotic compounds on other organ specific culprits such as hepatic stellate cells. The optical accessibility of the Scar-in-a-Jar has room for the introduction of one or more additional cell types like monocytes or smooth muscle cells to augment the fibrotic context and tailor it for a dermal wound healing situation or an atherosclerotic plaque. This could be done in direct coculture or using inserts, with the fibrotic target cells adhering to the bottom of the well. Besides preliminary testing of exogenously added matrix metalloproteinases [59], the current system has not yet been fathomed for its ability to study collagen matrix metalloproteinases turnover that would be relevant for analysing effects of collagen cross-link inhibitors and inducers of matrix metalloprtoteinases like hepatocyte growth factor. We envision longer observation times in this instance or challenging cell cultures after an initial ECM build-up, with additional cell types or substances that induce remodelling. A very promising line of research using this system could be non-enzymatic glycation studies to capture a diabetic situation and testing breakers of advanced glycation end products.

\section{Conclusions}

With the current burden of fibrosis worldwide and acquired connective tissue disorders as seen in diabetes, the development of in vitro test systems that mimic fibrosis and connective tissue formation is more needed than ever. The lack of adequate systems to study fibrogenesis in vitro has either impeded the development of antifibrotics or has forced research and development to move too early into animal models. Although in vivo evaluation is pivotal for preclinical development, a rapid in vitro quantitative screening method is mandatory for the first round determination of potential anti-fibrotic compounds, since any animal model represents the same complexity as a human and unclear in vitro data will unlikely be cleared in vivo. As there are several key points along the collagen biosynthesis pathway that can be interfered with, it is necessary to emulate all of these steps in vitro and, ideally, to get high content information out of a single well. This problem has been finally solved with the Scar-in-a-Jar. However, we look forward with great interest to seeing refinements and further developments of antifibrotics screening in the quest for the most potent and versatile antifibrotic compound.

\section{Abbreviations}

DAPI: 4',6-diamidino-2-phenylindole; DxS: dextran sulphate; ECM: extracellular matrix; EMT: epithelial-mesenchymal transition; Fc: Ficoll cocktail; HPLC: highperformance liquid chromatography; PAGE: polyacrylamide gel electrophoresis; SDS: sodium dodecyl sulphate; SMA: smooth muscle actin; TGF: transforming growth factor.

\section{Competing interests}

The authors declare that they have no competing interests.

\section{Authors' contributions}

Both CZCC and MR contributed equally to the writing of this manuscript.

\section{Acknowledgements}

The research leading to these results received funding from the National Medical Research Council (GPC 2004 Grant Number: R-397-000-0 I8-2 I3) and the Faculty Research Committee (R-397-000-032-102). We would like to thank the NUS Tissue Engineering Programme and the NUS Graduate School for Integrative Sciences and Engineering for their support.

\section{References}

I. Meltzer EB, Noble PW: Idiopathic pulmonary fibrosis. Orphanet J Rare Dis 2008, 3:8.

2. WHO: The Global Burden of Disease 2004 Update. Geneva: World Health Organization; 2004.

3. Cleutjens JP, Kandala JC, Guarda E, Guntaka RV, Weber KT: Regulation of collagen degradation in the rat myocardium after infarction. J Mol Cell Cardiol 1995, 27: I 28I-I 292.

4. Schmermund A, Schwartz RS, Adamzik M, Sangiorgi G, Pfeifer EA, Rumberger JA, Burke AP, Farb A, Virmani R: Coronary atherosclerosis in unheralded sudden coronary death under age 50: histo-pathologic comparison with 'healthy' subjects dying out of hospital. Atherosclerosis 200 I, 155:499-508.

5. Ratner BD, Bryant SJ: Biomaterials: where we have been and where we are going. Ann Rev Biomed Engineering 2004, 6:4 I-75.

6. Hilborn J, Bjursten LM: A new and evolving paradigm for biocompatibility. J Tissue Eng Regen Med 2007, 1:1 I0-I I9.

7. Thevenot P, Hu W, Tang L: Surface chemistry influences implant biocompatibility. Current Topics in Medicinal Chemistry 2008, 8:270-280.

8. Schiavone Panni A, Denti M, Franzese S, Monteleone M: The boneligament junction: a comparison between biological and artificial ACL reconstruction. Knee Surg Sports Traumatol Arthrosc 1993, 1:9-12.

9. Prescott RJ, Ryan WG, Bisset DL: Histopathological features of failed prosthetic Leeds-Keio anterior cruciate ligaments. J Clin Pathol 1994, 47:375-376.

10. Koschwanez HE, Yap FY, Klitzman B, Reichert WM: In vitro and in vivo characterization of porous poly-L-lactic acid coatings for subcutaneously implanted glucose sensors. J Biomed Materials Res 2008, 87:792-807.

II. Klueh U, Dorsky DI, Kreutzer DL: Enhancement of implantable glucose sensor function in vivo using gene transfer-induced neovascularization. Biomaterials 2005, 26: I I55-II63.

12. Jerosch J, Aldawoudy AM: Arthroscopic treatment of patients with moderate arthrofibrosis after total knee replacement. Knee Surg Sports Traumatol Arthrosc 2007, 15:71-77.

13. Ries MD, Badalamente M: Arthrofibrosis after total knee arthroplasty. Clin Orthopaedics Related Res 2000:177-183.

14. Ulrich D, Ulrich F, Pallua N, Eisenmann-Klein M: Effect of tissue inhibitors of metalloproteinases and matrix metalloproteinases on capsular formation around smooth and textured silicone gel implants. Aesthetic Plast Surg 2009, 33:555-562. 
15. Spano A, Palmieri B, Taidelli TP, Nava MB: Reduction of capsular thickness around silicone breast implants by zafirlukast in rats. Eur Surg Res 2008, $41: 8-14$

16. Rafael E, Wu GS, Hultenby K, Tibell A, Wernerson A: Improved survival of macroencapsulated islets of Langerhans by preimplantation of the immunoisolating device: a morphometric study. Cell Transplant 2003, I 2:407-4I2.

17. Dufrane D, Goebbels RM, Saliez A, Guiot Y, Gianello P: Six-month survival of microencapsulated pig islets and alginate biocompatibility in primates: proof of concept. Transplantation 2006, 8I:1345-I353.

18. Bellucci S, Chiaretti M, Cucina A, Carru GA, Chiaretti Al: Multiwalled carbon nanotube buckypaper: toxicology and biological effects in vitro and in vivo. Nanomed 2009, 4:53।-540.

19. Sahiner N, Kravitz DJ, Qadir R, Blake DA, Haque S, John VT, Margo $\mathrm{CE}$, Ayyala RS: Creation of a drug-coated glaucoma drainage device using polymer technology: in vitro and in vivo studies. Arch Ophthalmol 2009, 1 27:448-453.

20. Mavrikakis I, Francis N, Poitelea C, Parkin B, Brittain P, Olver J: Medpor lower eyelid spacer: does it biointegrate? Orbit 2009, 28:58-62.

21. Gristina AG: Implant failure and the immuno-incompetent fibro-inflammatory zone. Clin Orthopaedics Related Res 1994:106-118.

22. Tang L, Hu W: Molecular determinants of biocompatibility. Expert Rev Med Devices 2005, 2:493-500.

23. Riccetto C, Miyaoka R, de Fraga R, Barbosa R, Dambros M, Teixeira $A$, Palma P: Impact of the structure of polypropylene meshes in local tissue reaction:in vivo stereological study. Int Urogynecol J Pelvic Floor Dysfunct 2008, I 9: I I I 7-I I 23.

24. Liu L, Chen G, Chao T, Ratner BD, Sage EH, jiang S: Reduced foreign body reaction to implanted biomaterials by surface treatment with oriented osteopontin. J Biomaterial Sci 2008, 19:821-835.

25. Yoon SJ, Kim SH, Ha HJ, Ko YK, So JW, Kim MS, Yang YI, Khang G, Rhee JM, Lee HB: Reduction of inflammatory reaction of poly(d, I-lactic-co-glycolic Acid) using demineralized bone particles. Tissue Engineering 2008, 14:539-547.

26. Tang L, Eaton JW: Inflammatory responses to biomaterials. Am J Clin Pathology 1995, 103:466-47|

27. Chen ZC, Ekaputra AK, Gauthaman K, Adaikan PG, Yu H, Hutmacher $D W:$ In vitro and in vivo analysis of co-electrospun scaffolds made of medical grade poly(epsilon-caprolactone) and porcine collagen. J Biomater Sci Polym Ed 2008, 19:693-707.

28. Mendes JB, Campos PP, Rocha MA, Andrade SP: Cilostazol and pentoxifylline decrease angiogenesis, inflammation and fibrosis in sponge-induced intraperitoneal adhesion in mice. Life Sci 2009, 84:537-543.

29. Raghunath M, Sy Wong Y, Farooq M, Ge R: Pharmacologically induced angiogenesis in transgenic zebrafish. Biochem Biophysical Res Communications 2009, 378:766-77I.

30. Wynn TA: Common and unique mechanisms regulate fibrosis in various fibroproliferative diseases. J Clinicallinvestigation 2007, I I 7:524-529.

3I. Li C, Kong Y, Wang H, Wang S, Yu H, Liu X, Yang L, Jiang X, Li L, Li $L$ : Homing of bone marrow mesenchymal stem cells mediated by sphingosine I-phosphate contributes to liver fibrosis. J Hepatol 2009, 50: I 174-I I83.

32. Zavadil J, Bottinger EP: TGF-beta and epithelial-to-mesenchymal transitions. Oncogene 2005, 24:5764-5774.

33. Guarino M, Tosoni A, Nebuloni M: Direct contribution of epithelium to organ fibrosis: epithelial-mesenchymal transition. Hum Pathol 2009, 40:1365-76.

34. Raghunath $M$, Unsold $C$, Kubitscheck $U$, Bruckner-Tuderman L Peters R, Meuli M: The cutaneous microfibrillar apparatus contains latent transforming growth factor-beta binding protein-I (LTBP-I) and is a repository for latent TGF-betal. Invest Dermatol 1998, I I I:559-564.

35. Droguett R, Cabello-Verrugio C, Riquelme C, Brandan E: Extracellular proteoglycans modify TGF-beta bio-availability attenuating its signaling during skeletal muscle differentiation. Matrix Biol 2006, 25:332-34I.

36. Zhang Z, Li XJ, Liu Y, Zhang X, Li YY, Xu WS: Recombinant human decorin inhibits cell proliferation and downregulates TGF-betal production in hypertrophic scar fibroblasts. Burns 2007, 33:634-64I.
37. O'Kane S, Ferguson MW: Transforming growth factor betas and wound healing. Int J Biochem Cell Biol 1997, 29:63-78.

38. Ponticos M, Holmes AM, Shi-wen X, Leoni P, Khan K, Rajkumar VS, Hoyles RK, Bou-Gharios G, Black CM, Denton CP, Abraham DJ, Leask A, Lindahl GE: Pivotal role of connective tissue growth factor in lung fibrosis: MAPK-dependent transcriptional activation of type I collagen. Arthritis Rheum 2009, 60:2|42-2 I 55.

39. Liu Y, Wen XM, Lui EL, Friedman SL, Cui W, Ho NP, Li L, Ye T, Fan ST, Zhang $\mathrm{H}$ : Therapeutic targeting of the PDGF and TGFbeta-signaling pathways in hepatic stellate cells by PTK787I ZK22258. Lab lnvest 2009, 89: I I52-60.

40. Wynn T: Cellular and molecular mechanisms of fibrosis. Pathol 2007, 2 I 4: 199-2I0.

4I. Wynn TA, Cheever AW, Jankovic D, Poindexter RW, Caspar P, Lewis FA, Sher A: An IL-I 2-based vaccination method for preventing fibrosis induced by schistosome infection. Nature 1995, 376:594-596.

42. Wynn TA: Fibrotic disease and the $\mathbf{T}(\mathbf{H}) \mathbf{I} / \mathbf{T}(\mathbf{H}) 2$ paradigm. Nat Rev Immunol 2004, 4:583-594.

43. Grutter C, Wilkinson T, Turner R, Podichetty S, Finch D, McCourt M, Loning S, Jermutus L, Grutter MG: A cytokine-neutralizing antibody as a structural mimetic of 2 receptor interactions. Proc Natl Acad Sci USA 2008, 105:2025 I-20256.

44. Sumioka T, Ikeda K, Okada Y, Yamanaka O, Kitano A, Saika S: Inhibitory effect of blocking TGF-beta/Smad signal on injuryinduced fibrosis of corneal endothelium. Mol Vis 2008, 14:2272-228I.

45. Caballero S, Swaney J, Moreno K, Afzal A, Kielczewski J, Stoller G, Cavalli A, Garland W, Hansen G, Sabbadini R, Grant MB: Anti-sphingosine-I-phosphate monoclonal antibodies inhibit angiogenesis and sub-retinal fibrosis in a murine model of laserinduced choroidal neovascularization. Exp Eye Res 2009, 88:367-377.

46. Ikawa Y, Ng PS, Endo K, Kondo M, Chujo S, Ishida W, Shirasaki F, Fujimoto $M$, Takehara K: Neutralizing monoclonal antibody to human connective tissue growth factor ameliorates transforming growth factor-beta-induced mouse fibrosis. I Cell Physiol 2008, 21 6:680-687.

47. Fish PV, Allan GA, Bailey S, Blagg J, Butt R, Collis MG, Greiling D, James K, Kendall J, McElroy A, McCleverty D, Reed C, Webster R, Whitlock GA: Potent and selective nonpeptidic inhibitors of procollagen C-proteinase. J Medicinal Chem 2007, 50:3442-3456.

48. Lin X, Tammbara K, Fu M, Yamamoto M, Premaratne GU, Sakakibara Y, Marui A, Ikeda T, Komeda M, Tabata Y: Controlled release of matrix metalloproteinase I with or without skeletal myoblasts transplantation improves cardiac function of rat hearts with chronic myocardial infarction. Tissue Eng Part A 2009, 15:2699-2706.

49. Kaar JL, Li Y, Blair HC, Asche G, Koepsel RR, Huard J, Russell AJ: Matrix metalloproteinase-I treatment of muscle fibrosis. Acta biomaterialia 2008, 4: |4| I- | 420.

50. Hu PF, Chen H, Zhong W, Lin Y, Zhang X, Chen YX, Xie WF: Adenovirus-mediated transfer of siRNA against PAI-I mRNA ameliorates hepatic fibrosis in rats. J Hepatol 2009, 5 I: I 02-I I 3.

5I. Sato Y, Murase K, Kato J, Kobune M, Sato T, Kawano Y, Takimoto R, Takada K, Miyanishi K, Matsunaga T, Takayama T, Niitsu Y: Resolution of liver cirrhosis using vitamin A-coupled liposomes to deliver siRNA against a collagen-specific chaperone. Nature Biotechnology 2008, 26:43।-442.

52. Ferguson MW, Duncan J, Bond J, Bush J, Durani P, So K, Taylor L, Chantrey J, Mason T, James G, Laverty H, Occleston NL, Sattar A, Ludlow A, O'Kane S: Prophylactic administration of avotermin for improvement of skin scarring: three double-blind, placebo-controlled, phase I/II studies. Lancet 2009, 373: I 264-I 274.

53. Ghosh AK, Mori Y, Dowling E, Varga J: Trichostatin A blocks TGF-beta-induced collagen gene expression in skin fibroblasts: involvement of SpI. Biochem Biophysical Res Communications 2007, 354:420-426.

54. Wang Z, Chen C, Finger SN, Kwajah S, Jung M, Schwarz H, Swanson N, Lareu FF, Raghunath M: Suberoylanilide hydroxamic acid: a potential epigenetic therapeutic agent for lung fibrosis? Eur Respir J 2009, 34: I45-155.

55. Zion O, Genin O, Kawada N, Yoshizato K, Roffe S, Nagler A, lovanna $\mathrm{JL}$, Halevy O, Pines M: Inhibition of transforming growth factor beta signaling by halofuginone as a modality for pancreas fibrosis prevention. Pancreas 2009, 38:427-435. 
56. Olbrich KC, Meade R, Bruno W, Heller L, Klitzman B, Levin LS: Halofuginone inhibits collagen deposition in fibrous capsules around implants. Ann Plast Surg 2005, 54:293-296.

57. Cheng $\mathrm{K}$, Yang N, Mahato RI: TGF-betal gene silencing for treating liver fibrosis. Mol Pharm 2009, 6:772-779.

58. van Rooij E, Sutherland LB, Thatcher JE, DiMaio JM, Naseem RH, Marshall WS, Hill JA, Olson EN: Dysregulation of microRNAs after myocardial infarction reveals a role of miR-29 in cardiac fibrosis. Proceedings of the National Academy of Sciences of the United States of America 2008, I 05: I 3027-I 3032.

59. Chen CZ, Peng YX, Wang ZB, Fish PV, Kaar JL, Koepsel RR, Russell AJ, Lareu RR, Raghunath M: The Scar-in-a-Jar: studying potential antifibrotic compounds from the epigenetic to extracellular level in a single well. Br J Pharmacol 2009, I 58: I | 96- I 209.

60. Tschank G, Brocks DG, Engelbart K, Mohr J, Baader E, Gunzler V. Hanauske-Abel HM: Inhibition of prolyl hydroxylation and procollagen processing in chick-embryo calvaria by a derivative of pyridine-2,4-dicarboxylate. Characterization of the diethyl ester as a proinhibitor. Biochem J I99I, 275(Pt 2):469-476.

61. Lareu RR, Subramhanya KH, Peng Y, Benny P, Chen C, Wang Z Rajagopalan $R$, Raghunath M: Collagen matrix deposition is dramatically enhanced in vitro when crowded with charged macromolecules: the biological relevance of the excluded volume effect. FEBS Letters 2007, 581:2709-27I4.

62. Sauk J, Nikitakis N, Siavash H: Hsp47 a novel collagen binding serpin chaperone, autoantigen and therapeutic target. Front Biosci 2005, I 0:107-1 I8

63. Clark RA, McCoy GA, Folkvord JM, McPherson JM: TGF-beta stimulates cultured human fibroblasts to proliferate and produce tissue-like fibroplasia: a fibronectin matrix-dependent event. I Cellular Physiology 1997, I70:69-80.

64. Tambara K, Premaratne GU, Sakaguchi G, Kanemitsu N, Lin X, Nakajima H, Sakakibara Y, Kimura Y, Yamamoto M, Tabata Y, Ikeda T, Komeda M: Administration of control-released hepatocyte growth factor enhances the efficacy of skeletal myoblast transplantation in rat infarcted hearts by greatly increasing both quantity and quality of the graft. Circulation 2005 , I I 2:1129-134

65. Mias C, Lairez O, Trouche E, Roncalli J, Calise D, Seguelas $M H$ Ordener C, Piercecchi-Marti MD, Auge N, Salvayre AN, Bourin P Parini A, Cussac D: Mesenchymal Stem cells promote matrix metalloproteinase secretion by cardiac fibroblasts and reduce cardiac ventricular fibrosis after myocardial infarction. Stem Cells 2009, 27:2734-43.

66. Xu O, Norman IT, Shrivastav S, Lucio-Cazana J, Kopp JB: In vitro models of TGF-beta-induced fibrosis suitable for highthroughput screening of antifibrotic agents. Am J Physiology 2007, 293:F63I-640.

67. Hata R, Senoo H: L-ascorbic acid 2-phosphate stimulates collagen accumulation, cell proliferation, and formation of a three-dimensional tissuelike substance by skin fibroblasts. Cellular Physiology 1989, 138:8-16.

68. Murad S, Tajima S, Johnson GR, Sivarajah S, Pinnell SR: Collagen synthesis in cultured human skin fibroblasts: effect of ascorbic acid and its analogs. J linvestigative Dermatology | 983, 8 I: I 58- I62.

69. Yu YM, Ryan CM, Castillo L, Lu XM, Beaumier L, Tompkins RG, Young VR: Arginine and ornithine kinetics in severely burned patients: increased rate of arginine disposal. Am J Physiol Endocrinol Metab 200I, 280:E509-5I7.

70. Yu YM, Ryan CM, Burke JF, Tompkins RG, Young VR: Relations among arginine, citrulline, ornithine and leucine kinetics in adult burn patients. Am J Clin Nutr 1995, 62:960-968.

71. Barbul A: Proline precursors to sustain Mammalian collagen synthesis. I Nutr 2008, I 38:202IS-2024S

72. Ng KW, DeFrancis JG, Kugler LE, Kelly TA, Ho MM, O'Conor C], Ateshian GA, Hung CT: Amino acids supply in culture media is not a limiting factor in the matrix synthesis of engineered cartilage tissue. Amino Acids 2008, 35:433-438

73. Lareu RR, Arsianti I, Subramhanya HK, Yanxian P, Raghunath M: In vitro enhancement of collagen matrix formation and crosslinking for applications in tissue engineering: a preliminary study. Tissue Engineering 2007, I3:385-39|.

74. Peng $Y$, Raghunath $M$ : Learning from Nature: emulating macromolecular crowding to drive extracellular matrix enhancement for the creation of connective tissue. Tissue Engineering. Vienna: In Tech; 2009 in press.
75. Woessner JF Jr: The determination of hydroxyproline in tissue and protein samples containing small proportions of this imino acid. Arch Biochem Biophys 1961, 93:440-447.

76. Sweat F, Puchtler H, Rosenthal SI: Sirius Red F3ba as a stain for connective tissue. Arch Pathol 1964, 78:69-72.

77. Junqueira LC, Bignolas G, Brentani RR: Picrosirius staining plus polarization microscopy, a specific method for collagen detection in tissue sections. Histochem J 1979, I I:447-455.

78. Walsh BJ, Thornton SC, Penny R, Breit SN: Microplate readerbased quantitation of collagens. Analytical Biochem 1992 , 203: $187-190$

79. Houghton PE, Keefer KA, Diegelmann RF, Krummel TM: A simple method to assess the relative amount of collagen deposition in wounded fetal mouse limbs. Wound Repair Regen 1996, 4:489-495.

80. Tullberg-Reinert $\mathrm{H}$, Jundt $\mathrm{G}$ : In situ measurement of collagen synthesis by human bone cells with a Sirius Red-based colorimetric microassay: effects of transforming growth factor beta 2 and ascorbic acid 2-phosphate. Histochem Cell Biology 1999, I I 2:27|-276.

8I. Campa JS, McAnulty RJ, Laurent GJ: Application of high-pressure liquid chromatography to studies of collagen production by isolated cells in culture. Analytical Biochem 1990, I 86:257-263.

82. Stimler NP: High-performance liquid chromatographic quantitation of collagen biosynthesis in explant cultures. Analytical Biochem 1984, 142:103-108.

83. Tredget EE, Falk N, Scott PG, Hogg AM, Burke JF: Determination of 4-hydroxyproline in collagen by gas chromatography/mass spectrometry. Analytical Biochem 1990, 190:259-265.

84. Limeback HF, Sodek J: Procollagen synthesis and processing in periodontal ligament in vivo and in vitro. A comparative study using slab-gel fluorography. European J Biochem/FEBS I 979, I 00:54 I-550.

85. Raghunath $M$, Steinmann B, Delozier-Blanchet $C$, Extermann $P$ Superti-Furga A: Prenatal diagnosis of collagen disorders by direct biochemical analysis of chorionic villus biopsies. Pediatric Res 1994, 36:441-448.

86. Ramshaw JA, Werkmeister JA: Electrophoresis and electroblotting of native collagens. Analytical Biochem 1988, I 68:82-87.

87. Kirchhofer D, Reinhardt CA, Zbinden G: Collagen synthesis in growing human skin fibroblasts. Experimental Cell Biology I986, 54: $177-182$

88. Acharya PS, Zukas A, Chandan V, Katzenstein AL, Pure E: Fibroblast activation protein: a serine protease expressed at the remodeling interface in idiopathic pulmonary fibrosis. Hum Pathol 2006, 37:352-360.

89. Burchardt E-R, Schauer M, Stöcker W, Lampe T: Phosphinate peptide analogs for the treatment of fibrotic disorders. Phosphinate Peptide Analogs for the Treatment of Fibrotic Disorders, US Patent 6750202. City; 2004.

Publish with Biomed Central and every scientist can read your work free of charge

"BioMed Central will be the most significant development for disseminating the results of biomedical research in our lifetime. "

Sir Paul Nurse, Cancer Research UK

Your research papers will be:

- available free of charge to the entire biomedical community

- peer reviewed and published immediately upon acceptance

- cited in PubMed and archived on PubMed Centra

- yours - you keep the copyright 